\title{
O TEMPO ESCOLAR EM QUESTÃo
}

\author{
SCHOOL TIME IN QUESTION
}

EL TIEMPO ESCOLAR EN CUESTIÓN

\author{
Luciana Pacheco Marques \\ Cristiane Elvira de Assis Oliveira \\ Cristina Toledo \\ Josiane da Silva Andrade
}

\begin{abstract}
Resumo: Neste texto, objetivamos refletir sobre a questão do tempo escolar. Os espaços educacionais se estruturam em torno de uma certa organização de tempo que na Modernidade foi tão bem disseminado para/ em nossas escolas. Intentamos falar de um outro tempo, um tempo que está a ser vivido na Atualidade e refletir sobre os desdobramentos que isso traria para os espaços educacionais. Trazendo esta discussão para o nosso entendimento sobre a infância, precisamos atualizar nossa maneira de compreendê-la e, consequentemente, de pensar junto com ela sua educação. Pretendemos problematizar as seguintes questões: 0 que podemos refletir, então, sobre as implicações da mudança na noção de tempo para a escola? Como vivenciamos os tempos de aprendizagem? Como organizamos o tempo pedagógico? E como fica o tempo do professor e da professora diante de tantas indagações sobre o tempo? Qual deveria ser o tempo de permanência dos alunos e alunas na escola? Que espaços educacionais nos permitiriam viver o tempo como tempo de criação? Palavras-chave: Espaço. Tempo. Educação.
\end{abstract}

Abstract: In this paper, we aim to reflect on the issue of school time. Educational spaces are structured around a certain organization of time which has been extremely well spread to/in our schools in Modern Times. We try to speak of another time - a time that is to be experienced in Present Times - and reflect upon the consequences that this might bring to educational spaces. By bringing this discussion to our understanding of childhood, we need to update our ways to understand childhood and consequently to think about child education together with them. We intend to discuss the following questions: Thus, what can we reflect upon the implications of change in the notion of time for school? How do we experience learning time? How do we organize pedagogical time? And what about teacher's time in face of so many inquiries about time? What should the time of student schooling be? What educational spaces would allow us to live time as time for creation?

Keywords: Space. Time. Education.

Resumen: En este trabajo nos proponemos reflexionar sobre la cuestión del tiempo de la escuela. Los espacios educacionales se estructuran alrededor de una cierta organización de tiempo que en la Modernidad fue tan bien diseminado para/ en nuestras escuelas. Proponemos hablar de un otro tiempo, un tiempo que se vive en la Actualidad y reflexionar sobre los desdoblamientos que eso traería para los espacios educacionales. Trayendo esta discusión para el nuestro entendimiento sobre la infancia, necesitamos actualizar nuestra manera de comprenderla y consecuentemente pensar junto con ella su educación. Tenemos la intención de discutir las siguientes preguntas: ¿Qué podemos reflexionar entonces sobre las implicaciones del cambio en la noción de tiempo para la escuela? ¿Cómo vivenciamos los tiempos de aprendizaje? ¿Cómo organizamos el tiempo pedagógico? ¿Y como se queda el tiempo del profesor y de la profesora delante de tantas indagaciones sobre el tiempo? ¿Cuál debe ser el tiempo de permanencia de los alumnos y alumnas en la escuela? ¿Qué espacios educacionales nos permitirían vivir el tiempo como tiempo de creación?

Palabras clave: Escuela. Tiempo. Educación

Quem teve a idéia de cortar o tempo em fatias, a que se deu o nome de ano,

foi um indivíduo genial.

Industrializou a esperança, fazendo-a funcionar no limite da exaustão.

Doze meses dão para qualquer ser humano se cansar e entregar os pontos.

Aí entra o milagre da renovação

e tudo começa outra vez, com outro número e outra vontade de acreditar que daqui pra diante vai ser diferente.

(Cortar o tempo - DRUMMOND)

\section{INTRODUÇÃO}

Este texto emergiu de nossos estudos e de nossas reflexões tecidas no grupo de pesquisa, no qual buscamos (re)pensar a organização dos espaços-tempos escolares, contemplando as questões que se colocam para a escola na Atualidade ${ }^{2}$.

Os espaços educacionais estão relacionados a uma certa organização de tempo que na Modernidade foi tão bem disseminado para/ em nossas escolas. O tempo demarcado nas

\footnotetext{
*Artigo recebido junho 2013

Aprovado em junho 2013
} 
escolas sofre subordinação e fragmentação "cíclica" a cada ano através das séries, níveis/ etapas, de ciclos e graus de ensino, com o "tempo" certo de iniciar e terminar e dentro deste período com seus doze meses, seus bimestres, suas horas/aula.

Problematizaremos o tempo que Drummond enuncia na epígrafe deste texto, no caso escolar definido como ano letivo. No final de cada ano acreditamos que no próximo não mais nos depararemos com os desmandos da educação, nossos salários serão melhores, seremos reconhecidos de fato como profissionais, os alunos e alunas serão aprendizes competentes, as famílias se estruturarão, o prazer de lecionar retornará aos nossos corações. Intentamos falar de um outro tempo, um tempo que está a ser vivido na Atualidade, o agora, o acontecimento e refletir sobre os desdobramentos que isso nos traria para os espaços educacionais.

\section{AS NOÇÕES DE TEMPO E SUAS IMPLI- CAÇÕES PARA A ESCOLA}

Que tempo é esse de que trata a Modernidade? Que tempo é esse da Atualidade?

O presente é um traço marcante da Modernidade. Vaz (1997, p. 103), ao definir a Modernidade, a caracteriza como "a época da história porque ela se obrigou a pensar o acontecimento, uma certa experiência de tempo onde o passado e o futuro são momentos do próprio presente".

Sendo assim, no pensamento Moderno o presente constitui a emergência do possível, o qual se articula, por sua vez, ao universal, à humanidade. O que virá a ser, a novidade constitui o valor norteador da ação humana na Modernidade.

Sobre o tempo na Modernidade, Marques (2001, p. 35) afirma que:

O tempo é concebido de forma linear, onde os eventos constituem uma sucessão de acontecimentos cronologicamente ordenados. A relação entre o "era" (passado), o "não é mais" (presente) e o "vir a ser" (futuro) obedece, assim, a uma sucessão linear de mudanças.

A linearidade do tempo está, portanto, relacionada a essa relação entre passado, presente e futuro. Os acontecimentos obedecem a uma cronologia, o presente é tomado como referência para se pensar o passado e o futuro. Nas palavras de Oliva-Augusto (2002, grifo do autor), "O presente identifica o momento no qual, amparada pela experiência do passado e lançando mão da razão, a humanidade projetaria o seu futuro".

O futuro passa a ser visto como possível de se controlar, sendo que esse controle do futuro passa a ocorrer diante da crença na razão e no progresso, duas características imprescindíveis da Modernidade. Através de uma ilimitada confiança na razão acredita-se que a dominação dos princípios naturais em proveito do homem garantirá um futuro melhor à sociedade. Já diante da ideia de progresso, acredita-se que a ciência será capaz de levar a humanidade à passagem de um estágio menos desenvolvido para um mais desenvolvido, caracterizando assim o metarrelato ou a metanarrativa.

A visualização do futuro no presente passa a orientar a própria conduta humana. O futuro passa a ser almejado e buscado através das ações realizadas no presente, sendo configurado através das ações humanas (OLIVA-AUGUSTO, 2002).

Os rumos da humanidade vêm sendo redefinidos com o movimento de transição do pensamento do Mundo Moderno para o do Mundo Atual. Laclau (1992, p. 129) afirma que a compreensão dessa transição funda-se no entendimento de que "A pós-modernidade não pode ser uma simples rejeição da modernidade; em vez disso, ela envolve uma diferente modulação de seus temas e categorias, uma maior proliferação de jogos de linguagem".

A velocidade com que o mundo está mudando é assustadora. Estamos cada vez mais a mercê do efêmero, vivemos a incerteza. Estamos experimentando um novo modo de ser humano. Disso resulta uma forte crise de concepções, um conflito decorrente da coexistência de velhos e novos valores, gerando angústia pela necessidade de substituir o conhecido e o seguro pelo desconhecido. Nossas velhas concepções estão sendo postas em xeque e novas maneiras de nos relacionarmos com o mundo estão sendo construídas para preencher o lugar das velhas (MARQUES, 2001; MARQUES; MARQUES, 2003).

A mudança na noção de tempo, que deixa de ser pensado de forma linear, para ser considerado simultâneo é uma das marcas da Atualidade que mais nos instiga. Marques (2001) usa a metáfora de um leque para explicar o tempo nos dias de hoje, cujas varetas representariam, cada uma, a ocorrência de um evento, enquanto o seu conjunto representaria a simultaneidade de todos os eventos. O tempo se dá pela concomitância dos acontecimentos e não mais por sua expansão para o futuro.

Cada ser complexo é constituído por uma pluralidade de tempos, ramificados uns nos outros segundo articulações sutis e múltiplas. A história, seja a de um ser vivo ou de uma sociedade, não poderá nunca ser reduzida à simplicidade monótona de um tempo único, quer esse tempo cunhe uma invariância, quer trace os caminhos de um progresso ou de uma degradação (PRIGOGINE; STENGERS, 1997, p. 211).

Trazendo esta discussão para o nosso entendimento sobre a infância, precisamos atualizar nossa maneira de compreendê-la e, consequentemente, de pensar junto com ela sua educação. Como a infância pode ser pensada a partir dessas noções de tempo?

Sendo o tempo, na Modernidade, concebido como linear, como temos discutido até aqui, a infância passou a ser marcada por uma série de períodos que compõem o desenvolvimento 
humano, discurso este confirmado pela Psicologia e pela Medicina. Assim, a escola passou a ter a função de formar cada indivíduo para que no futuro ele se tornasse um bom cidadão. A Modernidade marcou bem a especificidade da criança, demarcando suas diferenças em relação ao adulto. A criança deixou de ser considerada o "adulto em miniatura" para ser pensada como um momento da vida em que há especificidades próprias. "Assim, a periodização encarcera a diferença da heterogeneidade da criança (suas maneiras próprias de pensar, sentir e agir) em quantidade, ou seja, incompletude, déficit, algo menos do que o adulto" (GUIMARÃES, 2002, p. 5).

As teorias sobre o desenvolvimento humano oriundas, principalmente, da Psicologia atuaram como regimes de verdade determinando como as crianças devem ser em cada momento da vida, em cada fase do desenvolvimento, produzindo a "infância normal". Como nos diz Kohan (2004, p. 2), "dividimos as crianças; as separamos, as antecipamos, as classificamos. As divisões são cada vez mais detalhadas e sofisticadas. Nossa precisão é crescente!".

De acordo com este autor, os saberes da História e da Psicologia têm se constituído como dispositivos que procuram "fixar a infância em torno de uma certa temporalidade" (KOHAN, 2004, p. 2).

Remetendo-nos aos antigos gregos, ele discute duas formas como o tempo era compreendido. Uma dessas formas é o chronos, que se refere ao tempo linear, sucessivo. "Há um modelo de temporalidade imutável, a eternidade, sem movimento; há um mundo em movimento, o mundo em que habitamos; numeramos esse mundo e o chamamos chronos" (KOHAN, 2004, p. 2).

$\mathrm{O}$ tempo-chronos se refere à soma entre o passado, o presente e o futuro. Há uma linearidade em que o presente se constitui como uma marca divisória entre o que já não é - o passado - e aquilo que está por vir, mas que ainda não é - o futuro.

O outro tempo discutido por Kohan (2004, p. 3) é o Aión. "Aión designa a intensidade do tempo da vida humana, um destino, uma duração, uma temporalidade não numerável nem sucessiva, intensiva".

Considerando essas duas temporalidades da infância, ela deixa de ser considerada apenas como uma etapa da vida, uma fase que precisa ser numerada e quantificada, passando a ser "um reinado que tem como marca uma intensidade. No reino infantil, que é o tempo, não há sucessão nem consecutividade, mas intensidade da duração" (KOHAN, 2004, p. 3).

Kohan (2004) não se refere à forma como a infância deve ser nem procura substituir uma temporalidade pela outra. As duas coexistem e uma não é excludente da outra. "Uma infância afirma a força do mesmo, do centro, do tudo; a outra, a diferença, o fora, o singular. Uma leva a consolidar, unificar e conservar; a outra a irromper, diversificar e revolucionar" (KOHAN, 2004, p. 6).

Podemos pensar, então, que sendo a escola parte constitutiva do todo social, ela refletirá todas as mudanças ocorridas nas concepções que significam a vida, transformando-se internamente e promovendo mudanças na ilimitada realidade do extramuro escolar.

Paulo Freire (1993, p. 10) nos incita a pensar esse movimento na/para a escola: "O tempo que levamos dizendo que para haver alegria na escola é preciso primeiro mudar radicalmente o mundo é o tempo que perdemos para começar a inventar e a viver a alegria".

A escola foi dividida em tempos e espaços determinados e estruturados e as crianças foram hierarquizadas dentro deles. Os espaços e tempos fixos que a Modernidade buscou levaram à homogeneização das turmas, afinal, era preciso que todos estivessem em um mesmo ponto do desenvolvimento para ocupar um determinado lugar em um determinado tempo. É a espacialização do tempo, o qual passou a ser redutível ao espaço e pensado em função do espaço (VEIGA-NETO, 2002).

O espaço e o tempo escolar não são neutros, e sim definidos pelos determinantes dos modos de ensino e aprendizagem. Eles também educam e fazem parte da cultura das instituições educativas.

Viñao Frago (1998) qualifica o tempo escolar simultaneamente como algo institucional, pessoal, cultural e individual. Afirma que o tempo é, do ponto de vista individual, plural e diverso, percebido e vivido distintamente por cada um dos participantes da escola: aluno, professor, direção. Ressalta ainda que o tempo é uma construção social em constante mudança e não é vivido apenas por aqueles que compartilham o espaço escolar, mas também pelas famílias e por toda a comunidade.

O que podemos refletir, então, sobre as implicações da mudança na noção de tempo para a escola? Como vivenciamos os tempos de aprendizagem? Como organizamos o tempo pedagógico?

Sampaio (2002), a partir do questionamento do porquê de algumas crianças chegarem ao final da $1^{\text {a }}$ série do ensino fundamental sem se apropriarem da linguagem escrita, se propôs a pesquisar a relação que poderia se estabelecer entre o tempo da criança e o tempo da escola, considerando o tempo de aprendizagem.

Ainda, Sampaio (2002), explicita que o tempo da escola é diferente do tempo das crianças, pois existe a expectativa de que todas aprendam num determinado tempo definido como série. A escola se prende a um paradigma homogeneizador que nega as diferenças.

\footnotetext{
As diferentes formas de perceber, de pensar, de sentir da criança passam a ser vistas como ausências de saber. Os caminhos percorridos pelas crianças, na maioria das vezes, desconhecidos para a escola, não são reconhecidos como passíveis de levar ao aprendizado. O que termina acontecendo é que as crianças
} 
que não acompanham o tempo da escola vão ficando para trás [...] Na medida em que a criança não acompanha o "tempo" da sua turma, que é o "tempo" imposto pela escola, ela é posta de "lado". A criança se perde no tempo, deixando de existir para a escola e para a professora como se o tempo para ela parasse (SAMPAIO, 2002, p. 186-187).

A linearidade do tempo faz com que as crianças que não se enquadram nele sejam consideradas como "diferentes". A valorização de uma determinada forma de compreender o tempo, como a valorização do tempo de aprendizagem pela escola, implica em qualificar aqueles que o utilizam da forma esperada. As outras formas de vivenciar o tempo passam a ser desqualificadas e passam a articular todas as manifestações das crianças em torno do tempo predominante, submetendo-as a seu ritmo. As crianças que não aprendem no ritmo esperado pela escola, por exemplo, estão sempre sendo comparadas àquelas que conseguem acompanhá-lo.

É necessário rediscutir o que a escola entende por tempo de aprendizagem. Sabemos que sujeitos diferentes, com histórias diferentes apreendem de múltiplas formas, pois o aprendizado não se limita ao intelecto, envolve também as emoções, sentimentos dos sujeitos, sendo assim, outras fontes de aprendizado não são consideradas. Considerar o tempo na Atualidade implica em que o olhar da escola se desloque do produto (aprovação/reprovação) para se identificar com o desenvolvimento, com o processo de aprendizagem que pode realizar (SAMPAIO, 2002).

Outra questão importante apontada por Sampaio (2002) diz respeito ao fato de o tempo pedagógico ser reduzido ao tempo utilizado no processo de aprendizagem de conteúdos dentro da sala de aula. O tempo de ensinar é reduzido ao espaço da sala de aula. O tempo do recreio, por exemplo, é considerado momento de perda de tempo pedagógico.

A escola trabalha com a concepção de aprendizagem que entende o aprender vinculado ao desempenho cognitivo e habilidades adquiridas pelos alunos. Desempenhos e habilidades predefinidos pela escola e/ ou pelo sistema educacional considerados universais, devendo ser atingidos em determinado tempo escolar (SAMPAIO, 2002, p. 188).

Gómez (2004) inicia a discussão sobre o "tempo escolar" com uma indagação: "Que escola queremos?", sinalizando que a estrutura espacial e temporal não dá oportunidade e vazão para a criatividade, coletividade, vivência sócio-cultural.

A rigidez e organização do tempo escolar formatado não atendem as particularidades dos sujeitos do cotidiano, ampliando muitas vezes somente a quantidade de tempo, enquanto a qualidade é posta em segundo plano. A uniformidade presente na organização escolar é apontada negativamente pela educadora (GÓMEZ, 2004), pois não se leva em conta o contexto social no qual a instituição está inserida, devendo ser flexível, singular e adaptado segundo suas características. A variabilidade de situações a que a escola está submetida vai de encontro à linearidade do currículo, do calendário, do planejamento e processo do ensino e aprendizagem.

O tempo pedagógico é fragmentado através das atividades da instituição balizadas pelo calendário como: os períodos festivos e comemorativos, avaliações, planejamentos, reuniões, férias, provas e outros (TEIXEIRA, 2004).

Os calendários escolares influenciam no redirecionamento, nas escolhas e formas didático-pedagógicas que a escola irá fazer, o que faz, o que prioriza, como pensa e age.

As escolas têm como parâmetro o calendário que as Secretarias de Ensino orientam através do calendário nacional com seus dias letivos definidos - o calendário oficial - e a partir destes as escolas individualmente organizam seus programas e atividades, de acordo com sua realidade - o calendário real (TEIXEIRA, 2004).

Os calendários são construções histórico-sociais que seguem cada povo e sua cultura, pelos quais se reconhecem, comemoram, relembram etc. Estes são carregados de sentidos e significados e têm a intervenção direta daqueles que detém o poder. "Instrumentos de controle social, como ocorre com outros signos temporais, os calendários são emblemas de poder e dominação, pois não apenas expressam, mas também circunscrevem os ritmos sociais" (TEIXEIRA, 2004, p. 22).

\footnotetext{
Embora o tempo siga seu curso, temos de tomar consciência de que nosso tempo deve ser algo próprio, algo que nos ocorre e em que podemos intervir ativamente, convertendo-o em um tempo vivido e sentido e conscientemente assumido por cada um de nós (GÓMEZ, 2004, p. 50).
}

No entender de Coelho (2002), tempo é continuidade. Assim, ao aproveitar o tempo curricular através de um projeto político-pedagógico crítico para a escola, propõe-se que o cotidiano escolar não se reduza à apreensão de conteúdos escolarizados, visualiza-se esse continuum do tempo curricular. A autora defende que precisamos ir além de uma segmentação dos conteúdos pedagógicos, explorando/enfocando alguns conhecimentos que não se reduzam ao tradicionalmente escolarizável.

Pensar no tempo enquanto continuidade nos desafia a pensar nas atividades de sala de aula como momentos de construção, de reflexão, tanto de professores e professoras como de alunos e alunas. O tempo de sala de aula deixa de ser aquele tempo de cumprir com as obrigações, de realizar atividades que se destinam a preencher a carga horária.

E como fica o tempo do professor e da professora diante de tantas indagações sobre o tempo? Falamos do tempo do aluno e da aluna, do tempo pedagógico, do tempo de aprendizagem... Qual é o tempo de reflexão do professor e da professora, de maneira que 
ele possa discutir com seus colegas sobre suas práticas, suas expectativas, suas angústias, enfim, momentos que Ihes proporcione uma reflexão sobre si mesmo e sobre sua prática pedagógica?

Mais uma vez, o que temos vivenciado nas escolas é a presença de um tempo cronometrado, visto que cada professor e cada professora entra para sua sala de aula no início do turno escolar e sai quando, ao bater o sinal, determina-se que o tempo acabou. Muitas vezes, o professor ou a professora não consegue conversar com o colega, com a direção, com os pais e mães de seus alunos e alunas, e seu tempo fica reduzido ao espaço e ao tempo da sala de aula.

Consideramos assim a necessidade de um tempo coletivo para os professores e professoras, no qual eles e elas possam discutir, refletir, aprender uns com os outros. No entender de Gómez (2004), tanto o tempo individual quanto o coletivo são muito importantes, pois diversas vezes a fragmentação e automatismo do tempo escolar não criam momentos preciosos e de satisfação para o desenvolvimento integral do sujeito.

A organização de um tempo coletivo traz para o cenário da escola a possibilidade de outras vozes se manifestarem. Os professores e as professoras podem expor suas opiniões e nessa troca de experiências e conhecimentos suas vozes passam a ter mais força, deixando de se submeterem a ordens. Esse tempo coletivo também é importante para que uma maior proximidade com os alunos e alunas e a comunidade possa acontecer nos espaços escolares. Acreditamos que todas essas vozes, professores e professoras, alunos e alunas, pais e mães, comunidade são importantes e que todos os seus conhecimentos devem ser valorizados no cotidiano escolar.

O tempo pedagógico na Atualidade solicita que a reflexão e planejamento do professor e da professora acompanhem a mudança da estrutura temporal. Desta forma, é preciso que: a jornada de trabalho dos professores e professoras não esteja vinculada em apenas transmitir conhecimento e controlar os alunos e alunas, devendo envolver o desenvolvimento profissional e o trabalho em equipe; haja adequação do calendário escolar conforme o contexto social, cultural e econômico do alunado; não seja ampliada a jornada escolar dos alunos e alunas desvinculados do que fazem, do que vivem, pois isto não trará a eles um aprendizado e uso do tempo útil e significativo (GÓMEZ, 2004).

Fazendo parte da questão do tempo pedagógico, uma outra questão tem se colocado envolvendo a temática do tempo. Qual deveria ser o tempo de permanência dos alunos e alunas na escola? E o que isso tem a ver com a mudança da noção de tempo na Atualidade?

Temos verificado que a chamada escola de educação em tempo integral tem se configurado em torno do aumento do tempo de per- manência dos alunos na escola, constituindo mais uma escola de tempo integral do que de educação integral.

Ao se propor a escola de educação em tempo integral como uma possibilidade de meIhoria do ensino, busca-se oferecer mais oportunidades de aprendizagem para as crianças, fazendo, em tempo integral, uma educação integral. Entendemos assim, mais tempo, como uma oportunidade de outra experiência escolar (CAVALIERE, 2007).

Certamente a discussão sobre educação integral vai muito além do aumento quantitativo do tempo de permanência dos alunos e alunas na escola, implica em pensar a educação do homem e da mulher integralmente na sua heterogeneidade.

Promover uma educação integral significa educar para outra educação possível. Ela acontece em todos os da vida e não se limita a temposespaços oficiais e formais de educação. Nós nos educamos ao longo de toda a vida, não temos como separar um tempo em que nos educamos de um outro em que não estamos nos educando. Estamos sempre aprendendo e ensinando, pois o tempo de aprender é aqui e agora, sempre (GADOTTI, 2009).

A educação integral implica uma noção de educação que não se confunde com horário integral, com tempo integral ou com jornada escolar (GADOTTI, 2009). Ampliar o tempo na escola requer uma educação integral em tempo integral. Assim, a ampliação do tempo escolar precisa vir acompanhada de uma outra visão de escola e do seu papel social (SILVA, 2002).

\section{CONSIDERAÇÕES FINAIS}

O desafio é constituirmos a escola num outro tempo, num tempo da Atualidade. O foco no presente nos faria viver cada momento como um acontecimento, sem pretensões de somar o número de aprendizagens para quantificá-la ao final do ano letivo, e a vivência do processo educacional fosse prazerosa cotidianamente. A mudança que se requer é no como vivenciamos os tempos de aprendizagem e pedagógico independentemente do tempo de permanência que temos, alunos e alunas, professores e professoras, na escola. "Um tempo para se pensar juntos, para decidir, coletivamente, o que fazer, como fazer, porque fazer [...] Um tempo [...], que podia 'ser tempo de criação' e não o que se vivia nos últimos anos [...] tempo de repetição" (SAMPAIO, 2002, p. 190).

Poderíamos, assim, romper com os espaços repletos de confinamentos vividos na Modernidade. A escola não se preocuparia mais com quem está "dentro" ou "fora" dos padrões estabelecidos como normais.

Que espaços educacionais nos permitiriam viver o tempo como "tempo de criação"? Certamente os espaços expandidos, interativos, ilimitados, flexíveis. Uma outra configuração espacial ainda por se fazer nas escolas, que 
rompam as barreiras das salas de aulas que homogeneízam os tempos das crianças de acordo com o tempo da escola. Uma organização tal que pense o espaço para todos, de forma que as diferenças sejam consideradas. De modo que o tempo pedagógico envolva todas as formas de conhecimento para além do conteudismo. Um espaço onde se viva a alegria de aprender a cada momento.

Garcia e Moreira (2003, p. 13) defendem, pois, que "a sala de aula deveria ser um riquíssimo espaço de diferentes saberes que se cruzam, entrecruzam, entram em conflito, produzindo novas possibilidades de compreensão do mundo e aumentando a compreensão que cada um pode ter de si mesmo".

Apontamos, já há algum tempo (MARQUES, 2006), algumas possibilidades para os elementos da prática escolar nesta perspectiva que defendemos: o planejamento se daria de forma participativa e coletiva, fortalecendo a interação entre escola, realidade social, teorias e práticas educacionais; os objetivos contemplariam a construção do conhecimento pelos alunos e alunas, o que sabem e o que precisam saber, levando em consideração sua realidade "socioantropológica"; na organização e seleção de conteúdos, metodologias e recursos, o trabalho individual e solitário do professor cederia lugar ao trabalho coletivo; buscar-se-ia coletivamente alternativas pedagógicas, bem como a conjugação de recursos didáticos e de metodologias convencionais com recursos alternativos e metodologias inovadoras; os professores e as professoras assumir-se-iam como "intercessores" na construção do conhecimento e não mais como meros transmissores de conteúdos estanques e desvinculados da realidade; os alunos e as alunas exercitariam o diálogo e a criatividade, atuando como coautores do processo educacional; a avaliação seria realizada em conjunto, levando em consideração o aluno e a aluna real (e não ideal), respeitando a bagagem cultural, a linguagem, as condições de aprendizagem e o ritmo próprio de cada um.

O campo de investigações sobre os usos do tempo no currículo ainda é campo aberto, e sua construção, considerando o tempo que dura inovador, podendo as experiências de construção currículos encarnados, trazer a alegria para as escolas, a alegria de ser professor e professora, aluno e aluna.

\section{NOTAS}

1. Este texto foi produzido a partir do projeto Tempos na escola coordenado pela Profa. Dra. Luciana Pacheco Marques, financiado pelo CNPq e FAPEMIG e apresentado no I Simpósio Espaço e Educação, realizado em 2007 pelo Núcleo de Educação em Ciência, Matemática e Tecnologia da Faculdade de Educação da Universidade Federal de Juiz de Fora (UFJF).
2. Momento atual marcado por uma forte crise de concepções, decorrentes da coexistência de veIhos e novos valores. Tal momento causa-nos inseguranças e incertezas, deixando-nos entregues a nós mesmas, ao mesmo tempo em que nos fascina - inaugura o tempo das descobertas e conquistas - nos angustia, apagando as certezas e gerando riscos desconhecidos. Com nossas noções e verdades abaladas, uma outra forma de perceber o mundo emerge.

\section{REFERÊNCIAS}

CAVALIERE, A. M. Tempo de escola e qualidade na educação pública. Educação \& Sociedade, Campinas, v. 28, n. 100, p. 10151035, out. 2007.

COELHO, L. M. C. C. Escola pública de horário integral: um tempo (fundamental) para o ensino fundamental. 2002. Disponível em: <http://www.educacaoonline.pro.br/escola_ publica.asp?f_id_artigo $=145>$. Acesso em: 20 jun. 2007.

FREIRE, P. Prefácio à edição brasileira. In: SNYDERS, G. Alunos felizes. São Paulo: Paz e Terra, 1993. p. 9-10.

GADOTTI, M. Educação integral no Brasil: inovações em processo. São Paulo: Editora e Livraria Paulo Freire, 2009.

GARCIA, R. L. ; MOREIRA, A. F. Começando uma conversa sobre currículo. In:

(Org.). Currículo na contemporaneidade: incertezas e desafios. São Paulo: Cortez, 2003. p. 7-39.

GÓMEZ, E. S. Outros tempos para outra escola. Pátio - Revista Pedagógica, n. 30, p. 47-50, maio/jul. 2004.

GUIMARÃES, D. Infância e educação: desafios modernos e pós-modernos - entre a criançaindivíduo e a criança-acontecimento. In: REUNIÃO ANUAL DA ANPED, 28., 2005, Caxambu. Anais eletrônicos... Rio de Janeiro: ANPE, 2005. Disponível em: <http://www. anped.org.br/reunioes/28/textos/gt07/ gt07375int.rtf>. Acesso em: 14 abr. 2007.

KOHAN, W. O. Apontamentos filosóficos para uma (nova) política e uma (também nova) educação da infância. In: REUNIÃO ANUAL DA ANPED, 27., 2004, Caxambu. Anais eletrônicos... Rio de Janeiro: ANPE, 2004. Disponível em: <http://www.anped.org.br/ reunioes/27/diversos/te_walter_kohan.pdf $>$. Acesso em: 14 abr. 2007.

LACLAU, E. A política e os limites da modernidade. In: HOLLANDA, Heloísa Buarque de. Pós-Modernismo e política. Rio de Janeiro: Rocco, 1992. p. 127-49. 
MARQUES, C. A. A imagem da alteridade na mídia. 2001. 248 f. Tese (Doutorado em Comunicação e Cultura) - Universidade Federal do Rio de Janeiro, Rio de Janeiro, 2001.

MARQUES, L. P. As implicações da inclusão no processo pedagógico. Inter-ação, Goiânia, v. 31, n. 2, p. 197-208, jul./ dez. 2006. Disponível em: <http://www. revistas.ufg.br/index.php/interacao/article/ view/1255/1285>. Acesso em: 26 nov. 2008.

MARQUES, L. P.; MARQUES, C. A. Do universal ao múltiplo: os caminhos da inclusão. In: LISITA, V. M. S. S. S.; SOUSA, L. F. E. C. P. (Org.). Políticas educacionais, práticas escolares e alternativas de inclusão escolar. Rio de Janeiro: DP\&A, 2003. p. 223-239.

OLIVA-AUGUSTO, M. H. Tempo, indivíduo e vida social. Ciência e Cultura, v. 54, n. 2, p. 30-33, out./dez. 2002. Disponível em: <http://cienciaecultura.bvs.br/scielo. php?script $=$ sci_arttext\&pid $=$ S0009$67252002000200025 \& \mathrm{lng}=\mathrm{en} \& \mathrm{nrm}=$ isso $>$. Acesso em: 20 jun. 2007.

PRIGOGINE, I.; STENGERS, I. A nova aliança: metamorfose da ciência. Brasília, DF: Ed. Universidade de Brasília, 1997.
SAMPAIO, C. S. Educação brasileira e(m) tempo integral. In: COELHO, Lígia M. C. C.; CAVALIERE, A. M. (Org.). Alfabetização e os múltiplos tempos que se cruzam na escola. Petrópolis: Vozes, 2002. p. 182-196.

SILVA, Y. R. de O. C. da. A proposta de alfabetização dos Centros Integrados de Educação Pública (CIEPs). In: COELHO, Lígia Martha Coimbra da Costa; CAVALIERE, Ana Maria Villela (Org.). Educação brasileira e (m) tempo integral. Petrópolis: Vozes, 2002. p. 168-181.

TEIXEIRA, I. A. C. Marcando o tempo: os calendários escolares. Pátio - Revista Pedagógica, n. 30, p. 20-23, maio/jul. 2004.

VAZ, P. Globalização e experiência de tempo. In: MENEZES, P. Signos plurais: mídia, arte e cotidiano na globalização. São Paulo: Experimento, 1997. p. 99-115.

VEIGA-NETO, A. De geometrias, currículo e diferenças. Educação \& Sociedade, Campinas, v. 23, n. 79, p. 163-186, ago. 2002.

VIÑAO FRAGO, A. Tiempos escolares, tiempos sociales - La distribución del tiempo y del trabajo em la enseñanza primaria em Espana (1838-1936). Barcelona: Ariel, 1998. 